\title{
Effects of passenger airplane transport on blood
}

\begin{abstract}
Objective: We examined the effects of passenger air transport by regular airplanes for air transportation on blood for transfusion.

Materials and methods: Irradiated red blood cell (RBC) solutions were transported by regular passenger airplanes which and were static in the cabin during the flight. Blood samples were evaluated visually and biochemically before and after transport. Hemolysis of the transported samples was compared to that of the non-transported ones. The vibration in the airplanes was also measured using a vibration data logger.
\end{abstract}

Results: There was no significant hemolysis of RBCs during airplane transport. The vibration in the airplane was lower than that in automobiles. The temperature in the active transport refrigerator (ATR) room was maintained at $2-6^{\circ} \mathrm{C}$. There was no significant hemolysis of RBCs during the two transport routes.

Conclusion: Temperature-controlled air transport of blood transport in the ATR 700 airplane maintained a the blood at a good quality that rendered blood it fit for blood transfusion.

Keywords: airplane, active transport refrigerator, red blood cell solution
Volume 8 Issue 5 - 2020

\author{
Koki Yakushiji, 'Takanori Yokochi, ${ }^{2}$ Hiroshi \\ Fujita, ${ }^{3}$ Fumiatsu Yakushiji ${ }^{4}$ \\ I Graduate School of Media and Governance, Keio University, \\ Japan \\ 2Japan Airlines Co., Ltd. Japan \\ ${ }^{3}$ Department of Transfusion Medicine, Tokyo Metropolitan \\ Bokutoh Hospital, Japan \\ ${ }^{4}$ Department of Internal Medicine, Tokyo Metropolitan Bokutoh \\ Hospital, Japan
}

Correspondence: Fumiatsu Yakushiji, MD, PhD, Director of Department of Internal Medicine, Tokyo Metropolitan Bokutoh Hospital, 4-23-15, Koutoubashi, Sumida-ku,Tokyo, I30-8575, Tel 8I-3-3633-6I5I; Fax, 8I-3-3633-6I73, Email clinic@nifty.com

Received: October 15, 2020 | Published: October 30, 2020
Abbreviations: RBC solution, red blood cell solution; ATR, active transport refrigerator; AST, aspartate aminotransferase; LD, lactate dehydrogenase; $\mathrm{Na}$, sodium; K, potassium

\section{Letter to the editor}

Blood for transfusion has been transported by drones in Africa, and drone transport has been tried attempted in the United States. ${ }^{1,2}$ However, we have earlier reported that the transport of blood by drones can be advantageous in the last single distance of transport in the transport process. ${ }^{3}$ We have considered the batoning of blood transport by multiple modes of transport. In particular, we suppose that the supply of blood over a wide region, especially in times of disaster, may include the transport of blood from aircrafts to other modes of transport, especially drones. Eventually, it is contemplated that single-range transport after aircraft transport could be performed by drones.

The effects of transport of on blood for transfusion by ships, motor vehicles, and drones have been evaluated. ${ }^{4-6}$ Although studies have evaluated the effects of transport of blood by drone after airplane transport, so far, the effects of the airplane transport itself were have not been evaluated. It was necessary to assess the effects of airplane transport on blood to eliminate the impact while considering the effects of the subsequent drone transport. Hence, we examined the effects of transport by regular airplanes for air transportation on blood for transfusion.

We divided the eight bags of irradiated red blood cell (RBC) solutions (each with two units of RBCs each [RBC \#1, \#2, \#3, and \#4]) obtained from the Japan Red Cross into two groups:; the flight group and the non-flight groups. The blood bags of the flight group were kept in an active transport refrigerator (ATR) (ATR700, Fujifilm Toyama Chemical Co. Ltd.; Tokyo, Japan) and then transported to Nagasaki (Japan Airlines 737-800; distance, 950 km from Tokyo; flight duration, $1 \mathrm{~h} 50 \mathrm{~min}$ ) in the ATR700. The bags were static in the cabin during the flight. The blood bags in the non-flight group (control) were stored at $4.0 \pm 0.3{ }^{\circ} \mathrm{C}$ in the laboratory. The blood samples were evaluated visually and biochemically (aspartate aminotransferase [AST], lactate dehydrogenase [LD], sodium [Na], and potassium [K] levels) before and after the transport. Hemolysis of RBC was compared between the flight and non-flight groups. The vibration in the airplane was measured with a Satotec USB vibration data logger DT-178A (acceleration sensor for transportation and logistics). All statistical analyses were performed using Excel version 2009. Data are expressed as mean \pm standard deviation, and the level of significance was set to $5 \%$.

The LD level is the most sensitive indicator of the RBC degradation of RBCs. The samples were taken from the RBC solutions on the one day before the test and one day later. Each sample was evaluated on an average of four sampling sessions. We calculated the rate of change in the LD level (LD ratio) with respect to the LD level before the test. The mean \pm standard deviation of the LD ratios for $\mathrm{RBC} \# 1$ before the test was were $1.1 \pm 0.1$-fold and $1.0 \pm 0.1$ (mean \pm standard deviation) for RBC \#1 (for the flight and non-flight groups, respectively) and 1.0 \pm 0.1 -fold for RBC \#1 (non-flight group). The $\mathrm{LD}$ ratios for $\mathrm{RBC} \# 1$ in the blood bags of the flight group after the airplane transport were $0.9 \pm 0.0$-fold and $1.2 \pm 0.2$-fold for the flight and of that of the non-flight groups, respectively. Similar calculations were performed for the other samples (RBC \#2,\#3, and \#4); however, most of the results were not significantly different. Only in RBC \#3 in the non-flight group had a higher, the LD ratio after filtering was higher in the blood left in the laboratory. This was thought to be due to the fact that the blood was not affected by transport (Table 1). All statical calculation performed using Excel version 2009. Data are expressed as mean \pm standard deviation. The level of significance $5 \%$. There were no visible changes in the blood bags. In terms of vibration, the wobble was smaller in flight than compared to that in an accelerating automobile or whilethe acceleration during automobile (car) transport and walking (Figure 1). Hence, we could infer that the air transportation of blood for transfusion by flight may not reduce its quality.

The results are expressed as mean $\pm \mathrm{SD}$. LD, lactate dehydrogenase; RBC, iIrradiated red blood cells. Most of the results were not significantly different. Only RBC \#3 in the non-flight group had a higher $\mathrm{LD}$ ratio after filtering only in $\mathrm{RBC} \# 3$, the $\mathrm{LD}$ ratio after 
filtering was higher in the blood left in the laboratory. However, since the LD ratio of blood after passage through the blood transfusion set that was left in the laboratory (non-flight group) is was high, it is not indicative of the effects of flight.

Table I LD ratio following airplane transport

\begin{tabular}{|c|c|c|c|c|}
\hline LD ratio & RBC \# I & RBC \#2 & RBC \#3 & RBC \#4 \\
\hline After flight (transport by a passenger aircraft) & $I . I \pm 0.1$ & $1.2 \pm 0.1$ & $0.9 \pm 0.1$ & $0.9 \pm 0.1$ \\
\hline Left in the laboratory & $1.0 \pm 0.1$ & $I, I \pm 0 . I$ & $0.9 \pm 0.1$ & $1.0 \pm 0.1$ \\
\hline Passage through blood transfusion set post-flight transport & $0.9 \pm 0.0$ & $0.9 \pm 0.0$ & $0.9 \pm 0.0 *$ & $I . I \pm 0.1$ \\
\hline Passage through blood transfusion set after being left in the laboratory & $1.2 \pm 0.2$ & $0.8 \pm 0.1$ & $I . I \pm 0.1 *$ & $1.0 \pm 0.1$ \\
\hline
\end{tabular}

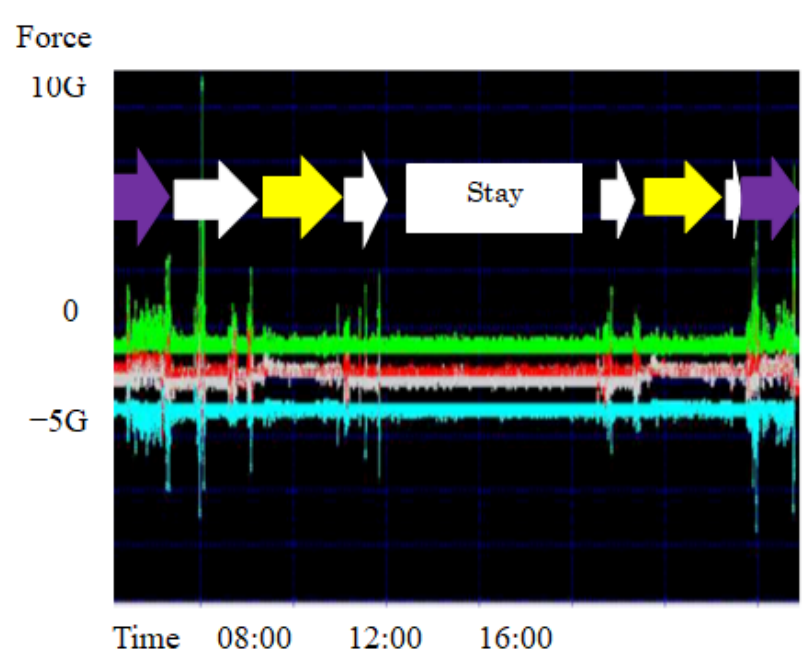

Figure I Recording of external forces during ATR transport in an active transport refrigerator.

The arrows indicate the movement of the active transport refrigerator ATR movement. Purple represents automobile movement, white represents walking, and yellow represents aircraft movement. The Total external forces are represented in green in the logger results: showed green for total external force, red for the $\mathrm{X}$-axis $\mathrm{X}$-component, pink for the $\mathrm{Y}$-component-axis, and light blue for the Z-axis component. It was clear that the total external forces on the, when blood carried in a passenger plane was less than that in an automobile. The large numbers when walking were artifacts of the location of the logger attachment.

We also transported samples between Tokyo and Osaka using a different flight model (Japan Airlines Boeing 787-8; distance, 510 $\mathrm{km}$; flight duration, $1 \mathrm{~h}$ ). Although the flight distance was shorter, the similar results were obtained were similar. The vibration data logger's record also showed that vibration in the cabin of an airliner was less than that in an automobile, and thiswhich may have contributed to preserving the might have preserved the quality of the blood. Furthermore, the two airplanes were pressurized, which and probably did not seem to affect the quality of the blood; nonetheless, there is room for further consideration in this regard. In conclusion, we have shown that the transport of blood for transfusion in a passenger aircraft under optimal temperature control $\left(4-6^{\circ} \mathrm{C}\right)$ does not degrade reduce its quality.

\section{Acknowledgments}

None.

\section{Conflicts of interest}

The authors declare no conflicts of interest.

\section{References}

1. Amukele T, Ness PM, Tobian AA, et al. Drone transportation of blood products. Transfusion. 2017;57(3):582-588.

2. Transfusion News. Drone delivery of blood products in South Africa. BioRad. June 12, 2019.

3. Yakushiji K, Fujita H, Murata M, et al. Short-range Transportation of Unmanned Aerial Vehicles (UAVs) during Disasters in Japan. Drones. 2020;4(4):68.

4. Igarashi T, Fujita $\mathrm{H}$, Asaka $\mathrm{H}$, et al. Patient rescue, and blood utilization in the Ogasawara blood rotation system. Transfusion. 2018;58:788-794.

5. Fujita H, Tojo Y, Mine T, et al. Temperature Management of Red Blood Cell Solution Transported by Car for Transfusion at Home. Open Journal of Blood Diseases. 2020;10:37-40.

6. Yakushiji K, Yakushiji F, Fujita H. Initial trial on the transport of blood Products using an unmanned aerial vehicle (UAV) in Japan in preparation for disaster. Hematol Trans Int J. 2019;7(3):77-78. 